\section{FINDING OUT WHAT MAKES YOU SMILE}

The Wrigley Company partnered with the FDI World Dental Federation for the second consecutive year to launch the 2009 FDI \& Wrigley Photographic Award and find out what makes dental care professionals smile.

Richard from Tacoma, Washington, USA was the grand winner of this year's award with this photo of children on a beach. He won an expenses paid trip to the 2010 FDI World Dental Congress in Salvador da Bahia, Brazil and as the North America regional winner, he also received the regional prizes of a $\$ 1,000$ voucher for photographic equipment, a one-year subscription to the International Dental Journal and a year's supply of Wrigley chewing gum.

'Partnering with Wrigley Oral Healthcare Programs (WOHP), we were able to provide the dental community with the chance to show us what makes them smile, and to highlight the importance of oral health as an integral part of overall general health,' said David Alexander, Executive Director of the FDI World Dental Federation.

Dental professionals from 63 counties around the world submitted photographs during the 2009 competition which ran from March 16-July 8. A variety of entries were received, including funny family photos, landscapes, friends having fun, animals and can-

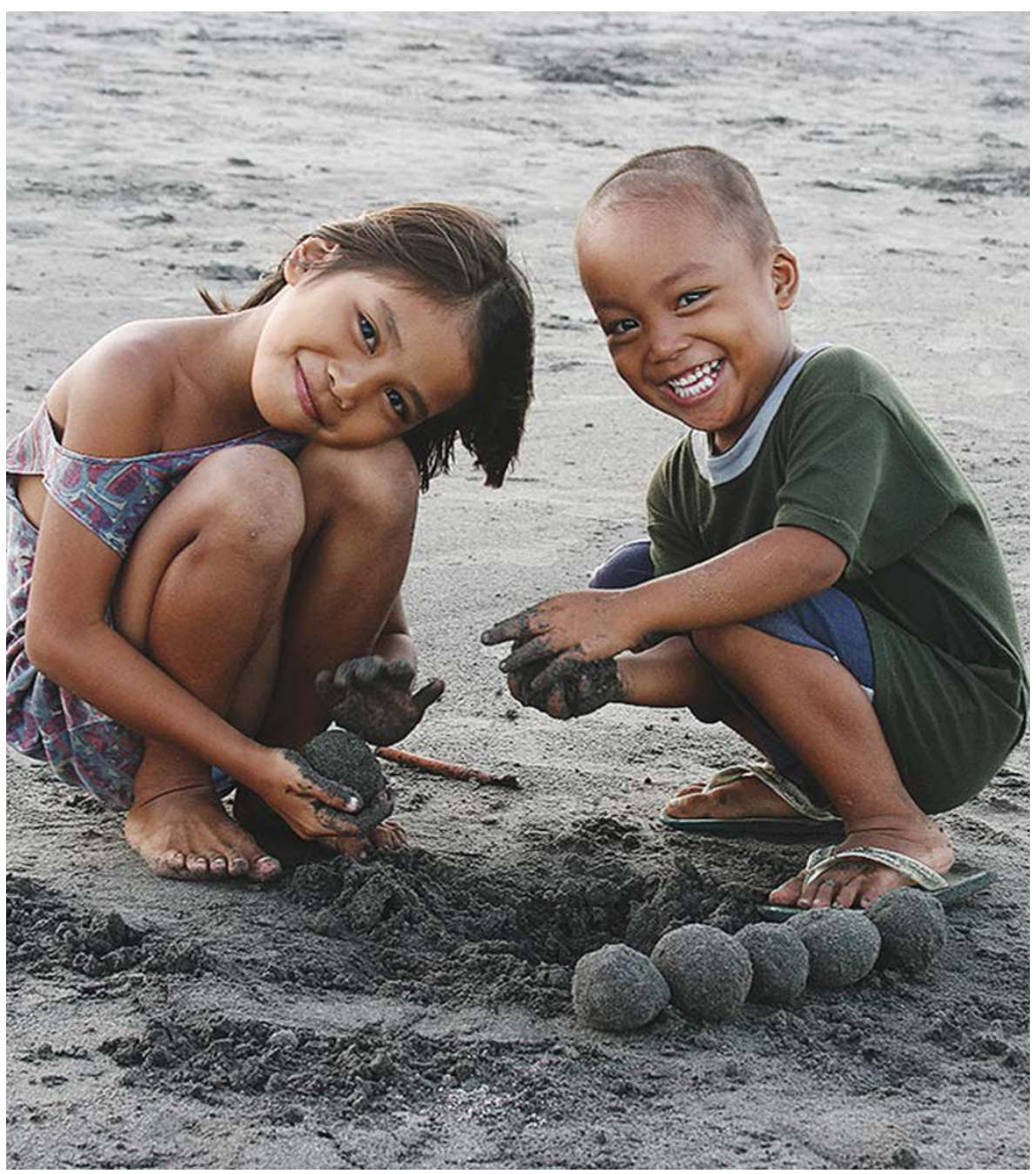

did shots of individuals. All of the photographs were reviewed by a panel of judges for creativity in addressing 'What makes you smile,' and six regional winners and one grand prize winner were selected.
In addition WOHP is donating $\$ 25,000$ to the FDI's World Dental Development Fund (WDDF), which supports oral health education and projects worldwide. For further information visit www.photoaward.org.

\section{NEW RESEARCH INTO ALCOHOL POLICY}

A team of national and international experts, led by an academic at the University of Sheffield, has been awarded funding from the Medical Research Council (MRC) to look at new methods of researching addiction.

The team will develop new approaches to effectively research UK alcohol policy, with the aim of delivering new knowledge to reduce the health and social harm caused by alcohol.

Dr Petra Meier, from the Sheffield's School of Health and Related Research (ScHARR), will lead the research cluster which will bring together alcohol researchers from across the UK, the USA, Australia and Canada and seek to closely engage with the Government and other policy stakeholders.

The research will form part of a wider initiative, led by the MRC and the Economic and Social Research Council (ESRC), to increase the capacity of addiction research in the UK by utilising the expertise of academics from a range of disciplines.

Alongside alcohol addiction, the initiative will look at addictions to drugs, gambling and tobacco, with the aim of improving research into these areas so that the major biological, social and medical problems in this field can be addressed. The team has recently gathered in Sheffield to initiate the project and is now working on developing their programme of work.

Dr Meier said, 'By developing our capacity to evaluate what works in alcohol policy, we are taking the first steps towards implementing real change to public health strategies. We are going to be using expertise from across the disciplines so that health, societal and economic problems in this field can be addressed, and we can reduce the harm caused by alcohol misuse.' 